\title{
LECTURAS Y APUNTES EN RELACIÓN CON EL LIBRO VOCES DE LA MONTAÑA. NATURALEZA Y SOCIEDAD EN EL SIGLO XX-VOLCÁN BARVA, COSTA RICA-, DE EMILIO VARGAS MENA
}

\author{
José Daniel Gil Zúñiga*
}

Palabras clave: historia oral; historia ambiental; medio ambiente; antropización; Emilio Vargas Mena; volcán Barva; Costa Rica.

Keywords: Oral History; Environmental History; Environment; Anthropization; Emilio Vargas Mena; Volcano Barva; Costa Rica.

Cuando no se es especialista en una temática -en este caso concreto la medioambiental-, y se le solicita a uno un comentario de un libro sobre el particular, siendo franco uno piensa que la tarea resulta difícil. Con esta perspectiva asumí la lectura de la obra, Voces de la montaña. Naturaleza y sociedad en el siglo XX-volcán Barva, Costa Rica- ${ }^{1}$ El libro de Emilio Vargas Mena me atrapó desde sus primeras líneas. Me sentí afín e íntimamente relacionado con lo que el autor iba exponiendo. ¿Qué fue lo que me atrajo de esta obra? De entrada lo sencillo de su redacción. El autor de manera amena y didáctica fue construyendo un argumento para que los no entendidos como yo pudieran

1 Emilio Vargas Mena, Voces de la montaña. Naturaleza y sociedad en el siglo XX-volcán Barva, Costa Rica-. Tomo I y Tomo II. Testimonios de historia ambiental (Heredia, Costa Rica: EUNA, 2016).

Fecha de recepción: 22/06/2017-Fecha de aceptación: 01/08/2017

* Costarricense. Doctor en Historia por la Universidad Autónoma de Barcelona. Investigador y profesor catedrático jubilado de la Escuela de Historia, Universidad Nacional (UNA), Costa Rica. Correo electrónico: jodagizu@gmail.com 
comprender lo que él, haciendo uso de estudios de la materia, documentos de primera mano, referencias científicas y sobre todo de "las voces de la montaña", quería demostrar.

Cuando el autor hace referencia a las especies de flora y fauna de la zona, no lo hace con el lenguaje cansino y pesado del que sabe, del que quiere demostrarnos el peso de su autoridad, sino con un lenguaje casi coloquial utilizado por el que quiere enseñar. Cuando la palabra no puede, surge el mapa, la foto que nos ilustra y que nos retrata la intimidad del espacio y de sus habitantes.

Los testimonios resumidos en el segundo tomo nos permiten ponerles cara a los informantes cuya voz hemos escuchado en la vibrante "pluma" del autor. La rápida revisión de dichos testimonios permite ir más allá de lo que el autor nos dio a conocer en el primer tomo. Los estudiosos de las mentalidades encontramos aquí un rico material que él supo explotar en forma clara y precisa, ya que sabía bien qué era lo que quería probar y en función de ello extrajo con rigurosidad de cada quien lo que necesitaba para hilvanar su argumento.

En la medida en que uno se va adentrando en la lectura de la obra va quedando dibujada la simbiosis entre los seres humanos y la naturaleza y los efectos que ello conlleva: "Las condiciones naturales imponen sus límites, pero la actividad humana encuentra las opciones de transformación del paisaje, experimenta y cambia su configuración, lo reinventa culturalmente como segunda naturaleza, algunas veces con resultados inesperados, peligrosos o catastróficos, ambiental y socialmente". Para quien lee, queda clara la relación entre paisaje natural, flora, fauna y seres humanos. Su visión teórica queda clara y entendible para los no letrados en este campo.

La lectura de este libro me hizo recordar viejas lecturas. Cuando el autor relata cómo bienes de uso se transforman en bienes de cambio y cómo parajes que antes eran de uso común en la medida que avanza y se consolida un régimen de propiedad sobre la tierra, pasan a ser propiedad privada tutelados por la ley y defendidos por los nuevos dueños con las limitaciones de apropiación que ello impone a los que antes hacían uso libre del espacio y de la flora y fauna que allí habitaba o merodeaba, no puedo dejar de recordar el caso del robo de leña señalado por Carlos Marx en una de sus primeras obras. Cuando analizo cómo el autor utiliza la relación espacio-tiempo, cómo metodológicamente hace uso de la misma y cómo enfrenta lo que él quiere demostrar, recuerdo a Stephen Hawking y su estudio sobre el Bing Bang.

Cuando leía al científico británico la pregunta que se me venía a la cabeza era, ¿Hawking es astrónomo o es historiador? Pronto me di cuenta que él era alguien que en ese libro estaba escribiendo un estado de la cuestión sobre el origen del universo y que estaba planteando un análisis en perspectiva histórica. Es decir era un astrónomo que hacía uso de la historia para construir su teoría. Al leer este libro de Emilio Vargas, me encontré con un ejercicio 
similar. El autor no es historiador, pero su estudio constituye un análisis en perspectiva histórica. Einstein ya lo había dicho, Hawking lo retoma y amplia y Emilio Vargas lo aterriza desde el espacio infinito a lo concreto del paisaje del volcán Barva: ¡El tiempo es! ¿Qué quiero decir con esto? Cualquiera que lea este libro -y los invito a que lo hagan- en cada capítulo de entrada se encuentra con una cita que nos remonta siglos atrás y que nos lanza imágenes de la relación entre la naturaleza y el poblamiento humano, luego viene la argumentación de un estudioso de la materia que sirve de enlace, como un puente tendido en el tiempo y que nos enlaza al presente en la voz de quien le sirvió de informante.

Al escribir estas líneas no puedo dejar de recordar que algo similar hizo Giovanni Levi en su libro La herencia inmaterial. Haciendo uso de esta estrategia teórica-metodológica el autor vuela por encima del tiempo, nos demuestra que efectivamente el tiempo es, pero no por ello borra el espacio, ni se deja de percibir el efecto positivo y nocivo del cambio tecnológico, de la presencia, desaparición de las especies de flora y fauna, el retorno de alguna de ellas, no deja de percibir el cambio en el paisaje, no se escapa el conflicto que todo ello genera y en lo cual no profundiza, ya que ese no era su objetivo, pero sobre todo no se le escapa la continuidad y el cambio, manifiesto y encerrado en la mentalidad y en las voces de sus informantes.

Con sus opiniones y sus sentimientos, el autor construye un puente entre el pasado y el presente y si cada capítulo se abre con una cita que evoca el pasado, cada uno concluye con una valoración personal desde el presente. Fino manejo de la inversión de la relación pasado-presente. El presente es el que muestra el producto de la huella del tiempo y el que fuerza a buscar y explicar el porqué de ello en el pasado.

En la explicación de ese proceso el autor se compenetra en su obra, es parte de ella. Es uno más en el paisaje. Viaja en el tiempo, con la habilidad que solo puede tener quien se compenetra con lo que estudia, nos parece verle en 1855, recorriendo los parajes del volcán a la par de Hoffmann, o treinta años más tarde, por los mismos lares con Henri Pittier, siendo testigo de la transformación del paisaje décadas atrás, o bien hace un par de años conversando con doña Carmen María Vargas Montero, en el portal de su casa.

$\mathrm{Su}$ verbo se hace denuncia cuando pone por escrito las quejas de los vecinos por el entubamiento de aguas y nacientes, pondera y valora el hecho, pero no lo hace desde la óptica del científico "que ve", el autor se compromete con la temática que estudia, pero sobre todo con los informantes a los cuales entrevistó, escuchó y a los cuales dio la voz; hoy sabemos por ellos mismos que los procesos de aculturación se dieron y no solo en lo que estrictamente llamamos cultura, sino también en algo relacionado con el agro como la importación de cierto tipo de ganado vacuno: “Aquí en Costa Rica, en lugar de 
crear nuestro propio sistema de lechería, con recursos del país, fuimos cada vez copiando más a los americanos, hasta llegar a tener una vaca muy grande y muy exigente en concentrados que la que los importábamos". Claro fortalecimiento del ciclo de dependencia tecnológica. La aculturación fortalecía la dependencia de los productos importados. Y las consecuencias para algunos son claras: "El rendimiento era mejor antes, con el ganado criollo. Era puro pasto lo que comía el animal en el potrero. Esas vacas rendían de 25 a 30 botellas de leche por ordeñe. Ahora no. Ahora hay que darles miel, cebada, concentrado, palote, tingrás y solo dan 15 botellas de leche. Además son muy caras por ser de raza. Una vaca de esas, pura, llega a valer hasta 250 mil colones. Las criollas llegaban a valer unos 70 mil colones". El autor, en apariencia, no denuncia, lo hacen sus informantes. Él es el medio que organiza las ideas. Su denuncia es política, a veces desgarradora, pero mesurada y ponderada y todo amparado en el peso de sus informantes, sus recuerdos y sus memorias.

Buen ejercicio de historia aplicada, que no es otra cosa que un análisis en perspectiva histórica. El libro confirma puntos de vista en torno a dicho tipo de análisis, sugiere vías de investigación que van desde cuestiones muy tecnológicas: las consecuencias de la importación de forrajes y especies de ganados, hasta otras relacionadas con la desaparición de platillos tradicionales de las mesas lugareñas y el imaginario en torno a leyendas y creencias sobrenaturales relacionadas con el volcán, la laguna y sus alrededores.

La obra plantea interrogantes, toda buena obra las deja y las mismas surgen no por fisuras en el argumento, sino porque la lectura las provoca: me llamó la atención el concepto de niñez que a veces aparece en estas páginas, pienso que este es un tema por investigar, ya que los que son llamados niños para el siglo XIX y primera mitad del siguiente ya eran hombres por las labores y deberes que tenían que asumir.

Con su análisis el autor nos invita a una bonita discusión que ya he abordado en un texto escrito años atrás. Cito en concreto la categoría espacio-tiempo, entendiendo la misma como una amalgama, ya que cada vez me convenzo más de que no tiene sentido escindir una de la otra y la metodología empleada por este autor me lo confirma.

Una última cuestión: detrás de esa relación que el autor establece entre medio ambiente, especies de flora y fauna, seres humanos y el peso de la transformación tecnológica cabe hacerse las siguientes preguntas: ¿Qué tanto cambian los actores mencionados en el proceso que el autor ha estudiado? ¿Qué tanto ha cambiado la relación entre los seres humanos, las especies y su entorno? ¿Qué tanto han cambiado las costumbres? ¿Cambian en su esencia o solo en su ropaje? ¿Cómo se expresan las continuidades y cambios? ¿Cómo se han adaptado las partes? 
Me hubiese gustado, y ya con esto finalizo, conocer los instrumentos con que el autor entrevistó a sus informantes, leer una breve presentación de la metodología utilizada. Mucho más me hubiese gustado escuchar de viva voz a sus informantes y digo todo esto porque como el libro se acompaña de un $\mathrm{CD}$ allí pudieron haberse incluido grabaciones y videos de las entrevistas y aunque en el mismo el autor nos presenta un segundo tomo titulado: Testimonios de historia ambiental del volcán Barva y allí quedan en extenso los argumentos de los informantes que él cita en el primer tomo, repito, me hubiese gustado escuchar las grabaciones para captar emotividades, subidas de tono, silencios de los informantes. Y digo esto porque este trabajo y sobre todo el segundo tomo es fuente de consulta para otros investigadores que armados con otras preguntas puedan explotar esos testimonios de manera distinta. Como sugerencia planteo que en futuras ediciones en el CD se incluya lo que se apunta en este párrafo.

Cierro el punto, la lectura de este libro me permitió conocer un estudio de lo ambiental, en donde este último huele a seres vivos, ya sean estos especies de la flora y fauna o seres humanos y me volvió a permitir entender el paisaje y la naturaleza como lo que efectivamente son: partes complementarias de los seres humanos que hemos tenido que aprehender a vivir en sociedades cada vez más tecnificadas. No se lea esto como una añoranza del pasado, al igual que Emilio Vargas no lo hago, simple y sencillamente y aquí lo cito a él, esto "es un modo de ver por la ventana del pasado hacia el futuro desde el presente". Una bella frase que condensa una manera de entender la historia. 